\title{
Which Behavior Change Techniques Are Effective in Promoting Physical Activity Among Older People With Dementia? A Call for Research Into Three Underexplored Avenues
}

People with dementia represent a growing proportion of the older adult population. Estimates suggest that 46.8 million people worldwide had dementia in 2015, and this figure will rise to 131.5 million by 2050 (Prince et al., 2015); with 90\% of people with dementia aged 65 years and older (World Health Organization [WHO], 2012). Dementia gradually impairs memory, executive functioning, and communication (Butler \& Radhakrishnan, 2012; Prince et al., 2015). Nonetheless, people with dementia should be encouraged to continue to enjoy good health for as long as possible as part of a public health strategy and for their continued quality of life (Ginis et al., 2017; Nyman \& Szymczynska, 2016).

Behavior change techniques (BCTs) are widely used in health promotion interventions and, in particular, the promotion of physical activity. However, the use of BCTs in physical activity promotion that rely on cognitive processes may be ineffective among people with dementia because of their cognitive impairment. There is currently no direct evidence to address this issue among people with dementia, and so, it is open to empirical study (van der Wardt et al., 2017). Inconclusive evidence comes from a recent systematic review of BCTs used to promote physical activity among people with dementia (Nyman, Adamczewska, \& Howlett, 2018). Although potential promise was found for goal setting (behavior), this BCT was not used in isolation, but was used with other BCTs that also had potential promise: social support (unspecified) and using a credible source. Therefore, the effectiveness of these three BCTs when used in isolation with people with dementia is unknown, and the remaining BCTs reviewed were either used too infrequently to identify potential promise or only used in ineffective interventions. Therefore, research is needed to identify which BCTs are effective in promoting physical activity among people with dementia.

In this editorial, I encourage physical activity researchers and clinicians working with older people with dementia to explore the use of approaches that do not rely on cognitive processes. These approaches may be shown to be more effective when working with people with cognitive impairment, given the nature of their condition, and stimulate novel strategies for encouraging uptake and adherence to physical activities. Further research might also illuminate when particular BCTs are more useful in considering the severity of an individual's dementia symptoms. People with dementia are heterogeneous and may have relatively mild, moderate, or severe symptoms. Therefore, the trajectory of use of BCTs that do not rely on cognitive processes may gradually become more useful as a person with dementia's cognitive functioning worsens. In the following editorial, I illustrate the predominant use of BCTs that rely on cognitive processes with reference to a widely used taxonomy of BCTs (Michie et al., 2013). I then propose three avenues of research where BCTs could be more effectively tested with people with dementia: partnership with carers, behaviorist approaches, and choice architecture.

\section{Predominant Use of BCTs That Rely on Cognitive Processes}

By way of illustration, a taxonomy of BCTs and two systematic reviews of BCTs used in physical activity interventions demonstrate the current predominant use of BCTs that rely on cognitive processes. A widely used taxonomy identified 93 BCTs to use in health promotion (Michie et al., 2013). Of these, the majority rely on cognitive processes $(n=65)$, with the remaining relying on nonconscious processes ( 18 and 10 that can be categorized under behaviorist and choice architecture approaches, respectively; see Supplementary Table S1 [available online]). Researchers have also predominantly used BCTs that rely on cognitive processes (see Sheeran, Klein, \& Rothman, 2017), as shown in a sample of two systematic reviews that have used Michie et al.'s (2013) taxonomy or similar with older people (French, Olander, Chisholm, \& McSharry, 2014) and people with dementia (Nyman et al., 2018; see Supplementary Table S2 [available online]). Similar observations can be drawn from other recently conducted systematic reviews of BCTs used to improve exercise adherence among older people (Room, Hannink, Dawes, \& Barker, 2017) and by physiotherapists to promote physical activity (Kunstler et al., 2018). From these systematic reviews, it is evident that the potential for BCTs that do not rely on cognitive processes is relatively underexplored. Rather than use BCTs that rely on the cognitive processing ability of people with dementia, three alternative approaches hold promise for future physical activity interventions, which are outlined below.

\section{Partnership With Carers}

The cognitive processing of informal carers could be enlisted to support people with dementia to engage with BCTs for the purpose of promoting physical activity. Enlisting the support of carers is perhaps the most frequently used approach by clinicians working with people with dementia (e.g., by physiotherapists codeveloping therapeutic goal plans). Carers could be effectively used in numerous BCTs, including sharing the task of setting goals, action and coping planning, or reminding the people with dementia of distal rewards. Although there is currently no direct evidence of shared cognitive processing for behavior change among people with dementia and their informal carers, there are some studies with the general adult population that have tested the use of working with couples rather than individuals to enact behavior change. For example, a randomized controlled trial tested a couple-based telephone intervention where individuals made goals and action plans for behavior change and their partners were encouraged to support these plans. Although the goals and plans were not jointly created by couples, the couplebased intervention led to an improvement in health behaviors, such as an increase in moderate physical activity and reduction in fat consumption, among patients who needed to reduce their cholesterol 
to avert coronary heart disease (Voils et al., 2013). Other studies suggest that the social support of a partner may well facilitate behavior-change efforts. For example, a study found that couples are more likely to increase their physical activity levels if both partners participate in a physical activity intervention than if only one partner participates or if there is no intimate partner (Gellert, Ziegelmann, Warner, \& Schwarzer, 2011).

Although there is potential for enlisting the support of carers of people with dementia in the use of BCTs to promote physical activity, a systematic review found self-regulatory BCTs to be associated with lower levels of both physical activity selfefficacy and behavior among adults aged 60 years and older (French et al., 2014). This is in contrast to previous systematic reviews that identified evidence for the use of self-regulatory BCTs with the general adult population to improve diet and physical activity participation (Greaves et al., 2011; Michie, Abraham, Whittington, McAteer, \& Gupta, 2009). A recent systematic review also suggests greater potential for self-regulatory BCTs to improve exercise adherence among older people (Room et al., 2017). In addition, as noted previously, a recent systematic review identified potential promise for the use of self-regulatory BCTs to promote physical activity among people with dementia (Nyman et al., 2018). Further experimental studies will be able to clarify the effectiveness of self-regulatory BCTs among older people and people with dementia, and under what conditions shared cognitive processing with an informal carer might facilitate behavior change.

As the symptoms of people with dementia worsen and they become more dependent on their informal carers, it is then likely that the role of the carer becomes increasingly important in facilitating physical activity. However, this may come at a cost to the carer and potentially lead to carer burden (van Alphen, Hortobágyi, \& van Heuvelen, 2016). In future research, there are four challenges that may arise when working in partnership with informal carers to promote physical activity. First, one assumes that there is an informal carer available to provide support for the people with dementia. In the United Kingdom, approximately a third of people with dementia in the community live alone and therefore are not supported by a spouse (Miranda-Castillo, Woods, \& Orrell, 2010). Second, for people with dementia who are supported by a spouse, the carer may not be able to support them in the prescribed manner. Informal caregivers themselves may have poor health; one study with informal carers found that $81.5 \%$ had at least one chronic illness and $60.5 \%$ had two or more (Wang, Robinson, $\&$ Carter-Harris, 2014). Measures of burnout and depression among carers of people with dementia have also been reported to be as high as $23-42 \%$ and $30 \%$, respectively (Schoenmakers, Buntinx, \& De Lepeleire, 2009; Truzzi et al., 2012). Third, some BCTs engage individuals to take ownership of their regular physical activity level through goal setting and a plan of implementation. If this process for the people with dementia is shared with their carer, then ownership of the goal and its associated plan may become diluted. This may become a barrier to adherence, especially if the memory of setting the goal and forming the action plan diminishes for the people with dementia. Prompting by the carer to continue to adhere to the action plan and reach the goal may then be perceived as being purely in the carer's interest, and performance of the behavior would shift from intrinsic motivation (to meet a goal that one wants to achieve) to extrinsic (to comply with another's wishes), which may negatively impact adherence (Deci \& Ryan, 2000). Fourth, the above approach assumes that people with dementia want to be supported by their informal carer, which is usually their spouse. A previous study has found that, for a weight-loss program, while women achieved greater weight loss when supported by their husband, men achieved greater weight loss when working alone (Wing, Marcus, Epstein, \& Jawad, 1991). Therefore, the demographic factors, individual circumstances, and wider sociocultural context may have great influence on the relationship dynamic and whether the people with dementia will be facilitated or inhibited in their physical activity behavior change by the support of their carer.

\section{Behaviorist Approaches}

Nonconscious approaches to promote health could be used as an alternative to relying on the cognitive processing ability of people with dementia. It has been demonstrated that people can learn behaviors implicitly, that is, via nonconscious processes (Hollands, Marteau, \& Fletcher, 2016; Marteau, Hollands, \& Fletcher, 2012; Zwart, Vissers, Kessels, \& Maes, 2017). Although the role of cognitive processes in implicit learning has been acknowledged (Kirsch, Lynn, Vigorito, \& Miller, 2004; Papies, 2016; Shanks \& St. John, 1994), the focus of behaviorist approaches is on nonconscious processes for behavior change (Johnston, 2015).

Behaviorist approaches such as operant and classical conditioning could be more widely applied with people with dementia to promote physical activity. Such approaches have been used in a therapeutic context to reduce unsociable behaviors and symptoms that can develop among people with dementia (Rabins, 1994). For example, operant conditioning has been used to reduce aggressive behavior among people with dementia in long-term care (Vaccaro, 1988). With classical conditioning, the pairing of two stimuli could develop the expectation of one feature in the environment arising upon the presentation of the other, and vice versa (Pavlov, 1927). For example, one could stimulate people with dementia to engage in exercise or facilitate their memory of particular exercises through repeated pairing of stimuli, such as always conducting them to the same music.

Previous studies have shown that people with dementia can learn behaviors implicitly via cue-outcome associations despite impaired explicit memory (Eldridge, Masterman, \& Knowlton, 2002). To promote physical activity, one could stimulate the development of muscle or kinesthetic memory, whereby movements are performed in a set pattern and are repeated. This would reflect other motor tasks that, once learned, are performed without conscious awareness (e.g., to ride a bike; Lally \& Gardner, 2013). This route of learning holds particular promise due to the simplicity of implicit learning approaches and because motor tasks are the last form of memory to decline in people with dementia (van Halterenvan Tilborg, Scherder, \& Hulstijn, 2007). However, the challenge for testing implicit learning BCTs is to design studies where they can be isolated from other BCTs. For example, classical conditioning experiments in care homes could be difficult to test if routines are already established that pair stimuli.

\section{Choice Architecture}

Another approach to the use of nonconscious processes for behavior change is choice architecture or "nudging" (Thaler \& Sunstein, 2008). The approach is not new, in that it builds on the last century's psychological and sociological knowledge of the impact of the environment on behavior. However, its appeal lies in encouraging people to adopt healthy behaviors without the use of legislation, regulation, or altering economic incentives (Marteau, 
Ogilvie, Roland, Suhrcke, \& Kelly, 2011). Choice architecture has potential for increasing public health by "nudging" people to choose a healthy behavioral choice at the point when the behavior is required. For example, this might involve encouraging people to use the stairs in a shopping center by displaying a sign at the elevator that informs people of the health benefits of using the stairs. The use of such signage or "point-of-decision prompts" has been effective in increasing stair use in public places (Soler et al., 2015).

For behavior change among people with dementia, this approach has promise as an avenue for future research, as its premise is that the desired behavior (e.g., walking up the stairs) is prompted by altering the environment to be performed immediately (i.e., does not require planning ahead or remembering to do an action later) and with minimal cognitive effort (i.e., not by attempting to change an individual's beliefs but only their behavior at that particular moment), assuming that the point-of-decision prompts are not cognitively demanding to read and process. The use of this approach may also be desirable for simultaneously achieving both public health and inclusivity agendas, including the promotion of active and healthy aging (Annear et al., 2014; WHO, 2002, 2010), and for communities and societies be more inclusive and "dementia friendly" (Department of Health, 2012; WHO, 2012). For example, environments designed to encourage people to be more physically active via noncognitively demanding interventions (e.g., making outdoor shopping areas more pleasant to walk around, providing benches for people to rest, and restricting motor traffic in such areas) may be effective in promoting physical activity for people of all ages and abilities. Choice architecture interventions may also be useful for dementia-specific contexts. For example, the frequency of behaviors among people with dementia that carers find challenging — disorientated walking, repetition (e.g., picking or vocalizations), and inappropriate sexual behavior-has been reduced in an institutional setting through changes to the environment, for example, through the use of color cues to reduce disorientated walking (Hussian, 1982).

However, caution has been raised about the lack of rigorous scientific evidence to support choice architecture (Marteau et al., 2011). The effectiveness of a choice architecture intervention would also depend on the nature of the specific intervention deployed and its context (Skov, LourenÇo, Hansen, Mikkelsen, \& Schofield, 2013). Recent work has provided a typology of choice architecture interventions in microenvironments and mapped available evidence to this typology (Hollands et al., 2013, 2017). However, there is currently no guidance on which specific choice architecture interventions should be deployed and with whom.

\section{Conclusion}

In testing the effectiveness of BCTs to promote physical activity, researchers have predominantly used approaches that rely on cognitive processes. Such approaches may be ineffective among people with dementia due to their cognitive impairment. Three avenues for future research have been proposed that may be more effective in promoting physical activity among people with dementia by drawing on the cognitive processing of others (partnership with carers) and by using nonconscious processes (behaviorist and choice architecture approaches). Researchers are encouraged to test the effectiveness of each of these promising approaches to identify when, where, and with whom such BCTs may be most effective in promoting physical activity among people with dementia to better promote health among this growing segment of the older adult population.

Samuel R. Nyman

Bournemouth University

\section{Acknowledgment}

The author is currently supported by a National Institute for Health Research Career Development Fellowship (grant number CDF-201508-030).

\section{References}

Annear, M., Keeling, S., Wilkinson, T., Cushman, G., Gidlow, B., \& Hopkins, H. (2014). Environmental influences on healthy and active ageing: A systematic review. Ageing \& Society, 34(4), 590-622. doi:10.1017/S0144686X1200116X

Butler, R., \& Radhakrishnan, R. (2012). Dementia: Systematic review 1001. BMJ Clinical Evidence. Retrieved from http://clinicalevidence .bmj.com/x/systematic-review/1001/overview.html

Deci, E.L., \& Ryan, R.M. (2000). The "what" and "why" of goal pursuits: Human needs and the self-determination of behavior. Psychological Inquiry, 11(4), 227-268. doi:10.1207/S15327965PLI1104_01

Department of Health. (2012). Prime Minister's challenge on dementia Delivering major improvements in dementia care and research by 2015. London, UK: Author.

Eldridge, L.L., Masterman, D., \& Knowlton, B.J. (2002). Intact implicit habit learning in Alzheimer's disease. Behavioral Neuroscience, 116(4), 722-726. PubMed ID: 12148939 doi:10.1037/0735-7044. 116.4.722

French, D.P., Olander, E.K., Chisholm, A., \& McSharry, J. (2014). Which behaviour change techniques are most effective at increasing older adults' self-efficacy and physical activity behaviour? A systematic review. Annals of Behavioral Medicine, 48(2), 225-234. PubMed ID: 24648017 doi:10.1007/s12160-014-9593-Z

Gellert, P., Ziegelmann, J.P., Warner, L.M., \& Schwarzer, R. (2011). Physical activity intervention in older adults: Does a participating partner make a difference? European Journal of Ageing, 8(3), 211219. PubMed ID: 28798651 doi:10.1007/s10433-011-0193-5

Ginis, K.A., Heisz, J., Spence, J.C., Clark, I.B., Antflick, J., Ardern, C.I., ... Rotondi, M.A. (2017). Formulation of evidence-based messages to promote the use of physical activity to prevent and manage Alzheimer's disease. BMC Public Health, 17(1), e209. doi:10. 1186/s12889-017-4090-5

Greaves, C.J., Sheppard, K.E., Abraham, C., Hardeman, W., Roden, M., Evans, P.H., ... IMAGE Study Group. (2011). Systematic review of reviews of intervention components associated with increased effectiveness in dietary and physical activity interventions. BMC Public Health, 11, e119. doi:10.1186/1471-2458-11-119

Hollands, G.J., Bignardi, G., Johnston, M., Kelly, M.P., Ogilvie, D., Petticrew, M., ... Marteau, T.M. (2017). The TIPPME intervention typology for changing environments to change behaviour. Nature Human Behaviour, 1, 0140. doi:10.1038/s41562-017-0140

Hollands, G.J., Marteau, T.M., \& Fletcher, P.C. (2016). Non-conscious processes in changing health-related behaviour: A conceptual analysis and framework. Health Psychology Review, 10(4), 381-394. doi:10.1080/17437199.2015.1138093

Hollands, G.J., Shemilt, I., Marteau, T.M., Jebb, S.A., Kelly, M.P., Nakamura, R., . . Ogilvie, D. (2013). Altering micro-environments to change population health behaviour: Towards an evidence base for 
choice architecture interventions. BMC Public Health, 13, e1218. doi:10.1186/1471-2458-13-1218

Hussian, R.A. (1982). Stimulus control in the modification of problematic behavior in elderly institutionalized patients. International Journal of Behavioral Geriatrics, 1(1), 33-42.

Johnston, M. (2015). What more can we learn from early learning theory? The contemporary relevance for behaviour change interventions. British Journal of Health Psychology, 21(1), 1-10. PubMed ID: 26482915 doi:10.1111/bjhp.12165

Kirsch, I., Lynn, S.J., Vigorito, M., \& Miller, R.R. (2004). The role of cognition in classical and operant conditioning. Journal of Clinical Psychology, 60(4), 369-392. PubMed ID: 15022268 doi:10.1002/ jclp. 10251

Kunstler, B.E., Cook, J.L., Freene, N., Finch, C.F., Kemp, J.L., O'Halloran, P.D., \& Gaida, J.E. (2018). Physiotherapists use a small number of behaviour change techniques when promoting physical activity: A systematic review comparing experimental and observational studies. Journal of Science and Medicine in Sport, 21(6), 609-615. PubMed ID: 29233466 doi:10.1016/j.jsams.2017. 10.027

Lally, P., \& Gardner, B. (2013). Promoting habit formation. Health Psychology Review, 7(Suppl. 1), S137-S158. doi:10.1080/ 17437199.2011.603640

Marteau, T.M., Hollands, G.J., \& Fletcher, P.C. (2012). Changing human behavior to prevent disease: The importance of targeting automatic processes. Science, 337, 1492-1495. PubMed ID: 22997327 doi:10. 1126/science. 1226918

Marteau, T.M., Ogilvie, D., Roland, M., Suhrcke, M., \& Kelly, M.P. (2011). Juding nudging: Can nudging improve population health? BMJ, 342, d228. PubMed ID: 21266441 doi:10.1136/bmj.d228

Michie, S., Abraham, C., Whittington, C., McAteer, J., \& Gupta, S. (2009). Effective techniques in healthy eating and physical activity interventions: A meta-regression. Health Psychology, 28(6), 690-701. PubMed ID: 19916637 doi:10.1037/a0016136

Michie, S., Richardson, M., Johnston, M., Abraham, C., Francis, J., Hardeman, W., ... Wood, C.E. (2013). The behavior change technique taxonomy (v1) of 93 hierarchically clustered techniques: Building an international consensus for the reporting of behavior change interventions. Annals of Behavioral Medicine, 46(1), 81-95. PubMed ID: 23512568 doi:10.1007/s12160-013-9486-6

Miranda-Castillo, C., Woods, B., \& Orrell, M. (2010). People with dementia living alone: What are their needs and what kind of support are they receiving? International Psychogeriatrics, 22(4), 607-617. PubMed ID: 20214844 doi:10.1017/S104161021000013X

Nyman, S.R., Adamczewska, N., \& Howlett, N. (2018).Systematic review of behaviour change techniques to promote participation in physical activity among people with dementia. British Journal of Health Psychology, 23(1), 148-170. PubMed ID: 28980370 doi:10.1111/ bjhp.12279

Nyman, S.R., \& Szymczynska, P. (2016). Meaningful activities for improving the wellbeing of people with dementia: Beyond mere pleasure to meeting fundamental psychological needs. Perspectives in Public Health, 136(2), 99-107. PubMed ID: 26933079 doi:10.1177/ 1757913915626193

Papies, E.K. (2016). Health goal priming as a situated intervention tool: How to benefit from nonconscious motivational routes to health behaviour. Health Psychology Review, 10(4), 408-424. PubMed ID: 27144729 doi:10.1080/17437199.2016.1183506

Pavlov, I.P. (1927). Conditioned reflexes. Oxford, UK: Oxford University Press.

Prince, M., Wimo, A., Guerchet, M., Ali, G.-C., Wu, Y.-T., \& Prina, M. (2015). World Alzheimer report 2015. The global impact of dementia:
An analysis of pravalence, incidence, cost and trends. London, UK: Alzheimer's Disease International.

Rabins, P.V. (1994). The phenomenology of behavior: An overview of behavioral principles. Alzheimer Disease \& Associated Disorders, 8(Suppl. 3), 61-65. doi:10.1097/00002093-199404000-00006

Room, J., Hannink, E., Dawes, H., \& Barker, K. (2017). What interventions are used to improve exercise adherence in older people and what behavioural techniques are they based on? A systematic review. BMJ Open, 7(12), e019221. PubMed ID: 29247111 doi:10.1136/bmjopen2017-019221

Schoenmakers, B., Buntinx, F., \& De Lepeleire, J. (2009). The relation between care giving and the mental health of caregivers of demented relatives: A cross-sectional study. European Journal of General Practice, 15(2), 99-106. PubMed ID: 19579153 doi:10.1080/ 13814780903064455

Shanks, D.R., \& St. John, M.F. (1994). Characteristics of dissociable human learning systems. Behavioral and Brain Sciences, 17(3), 367395. doi:10.1017/S0140525X00035032

Sheeran, P., Klein, W.M.P., \& Rothman, A.J. (2017). Health behavior change: Moving from observation to intervention. Annual Review of Psychology, 68, 573-600. PubMed ID: 27618942 doi:10.1146/ annurev-psych-010416-044007

Skov, L.R., LourenÇo, S., Hansen, G.L., Mikkelsen, B.E., \& Schofield, C. (2013). Choice architecture as a means to change eating behaviour in self-service settings: A systematic review. Obesity Reviews, 14, 187196. PubMed ID: 23164089 doi:10.1111/j.1467-789X.2012.01054.x

Soler, R.E., Leeks, K.D., Buchanan, L.R., Brownson, R.C., Heath, G.W., Hopkins, D.H., \& Task Force on Community Preventive Services. (2015). Point-of-decision prompts to increase stair use: A systematic review update. American Journal of Preventive Medicine, 38(2S), S292-S300.

Thaler, R.H., \& Sunstein, C.R. (2008). Nudge: Improving decisions about health, wealth and happiness. London, UK: Yale University Press.

Truzzi, A., Valente, L., Ulstein, I., Engelhardt, E., Laks, J., \& Engedal, K. (2012). Burnout in familial caregivers of patients with dementia. Revista Brasileira de Psiquiatria, 34(4), 405-412. PubMed ID: 23429811 doi:10.1016/j.rbp.2012.02.006

Vaccaro, F.J. (1988). Application of operant procedures in a group of institutionalized aggressive geriatric patients. Psychology and Aging, 3(1), 22-28. PubMed ID: 3268239 doi:10.1037/0882-7974.3.1.22

van Alphen, H.J.M., Hortobágyi, T., \& van Heuvelen, M.J.G. (2016). Barriers, motivators, and facilitators of physical activity in dementia patients: A systematic review. Archives of Gerontology and Geriatrics, 66, 109-118. PubMed ID: 27295140 doi:10.1016/j.archger. 2016.05.008

van der Wardt, V., Hancox, J., Gondek, D., Logan, P., Nair, R.D., Pollock, K., \& Harwood, R. (2017). Adherence support ons in people with mild cognitive impairment and dementia: A systematic review. Preventive Medicine Reports, 7, 38-45. PubMed ID: 28593121 doi:10.1016/j.pmedr.2017.05.007

van Halteren-van Tilborg, I.A.D.A., Scherder, E.J.A., \& Hulstijn, W. (2007). Motor-skill learning in Alzheimer's disease: A review with an eye to the clinical practice. Neuropsychology Review, 17(3), 203212. PubMed ID: 17680369 doi:10.1007/s11065-007-9030-1

Voils, C.I., Coffman, C.J., Yancy, W.S., Jr., Weinberger, M., Jeffreys, A.S., Datta, S., . . . Bosworth, H.B. (2013). A randomized controlled trial to evaluate the effectiveness of CouPLES: A spouse-assisted lifestyle change intervention to improve low-density lipoprotein cholesterol. Preventive Medicine, 56(1), 46-52. PubMed ID: 23146744 doi:10.1016/j.ypmed.2012.11.001

Wang, X.R., Robinson, K.M., \& Carter-Harris, L. (2014). Prevalence of chronic illnesses and characteristics of chronically ill informal 
caregivers of persons with dementia. Age and Ageing, 43(1), 137141. PubMed ID: 24072413 doi:10.1093/ageing/aft142

Wing, R.R., Marcus, M.D., Epstein, L.H., \& Jawad, A. (1991). A “familybased" approach to the treatment of obese type II diabetic patients. Journal of Consulting and Clinical Psychology, 59(1), 156-162. PubMed ID: 2002132 doi:10.1037/0022-006X.59.1.156

World Health Organization. (2002). Active ageing: A policy framework. Geneva, Switzerland: Author.
World Health Organization. (2010). Global recommendations on physical activity for health. Geneva, Switzerland: Author.

World Health Organization. (2012). Dementia: A public health priority. Geneva, Switzerland: Author.

Zwart, F.S., Vissers, C.T.W.M., Kessels, R.P.C., \& Maes, J.H.R. (2017). Procedural learning across the lifespan: A systematic review with implications for atypical development. Journal of Neuropsychology. Advance online publication. doi:10.1111/jnp.12139 